\title{
Gender posed: The people behind the postcards
}

\section{Greg Ringer}

\section{Introduction}

As the world's largest service industry, tourism is increasingly perceived by proponents as a socioeconomic panacea for indigenous communities. A central tenet of this argument presumes that tourism can help ensure environmental conservation and simultaneously, both employ and empower women and ethnic minorities. Yet, the selling of local people and their practices as tourist "attractions" too often transfigures the social history and culturally-constructed landscapes of the destination by mediating the formation of identities long defined through gender, behavior, and belief. This chapter, therefore, highlights the evolving roles of women and men in the globalization of tourism, as they decipher and interpret their history and "place" as visitors and denizens of locations increasingly (re)defined by the images and discourse of travel marketing. More specifically, it examines the interplay between gender and tourism by drawing attention to the 1) manner by which our spatial and cognitive experiences as hosts and visitors - and the resultant choice of destinations and leisure activities for either enjoyment or employment - are shaped by cultural constructions, perceptual images, and social practices of gender and sexuality, including prescribed clothing and physical appearances, ritualized behavior, and notions of work and equity; and 2) venues where tourism, as an industry and a socioeconomic sphere of human activity, might engender positive change at the local and international levels in existing social, environmental, and financial conditions. In so doing, the following research is intended to encourage both critical - and creative - appreciation and further discussion of the direction and discourse of tourism development and marketing in the magnification and marginalization of cultural traditions and local heritage.

\section{Tourism and Gender Intersects}




\section{Chapter Thirteen}

The nexus of tourism and gender lies, in part, in the human constructions of the destination, both architectural and emotive, and the quality and context of peoples' encounters with the attraction (figure 13.1). A major employer of women and ethnic minorities, the experience, identity, and meaning of travel in many communities have long been defined by the nature of the recreational act, including whether an individual engages as a user of the resource or activity, an employee, or the cultural or sexual object. Equally decisive are the ideologies, images, and material transactions of tourism, with traditional practices, artifacts, and attire once historically prescribed by gender and sexualized behavior, now reinforced in value by tourism or conversely, demeaned through commercial trade, entertainment, and sex tourism (Opperman, 1998; Ringer, 1998; Aitchison, et al., 2000; Mansvelt, 2005).

[Figure 13.1. about here]

Stylized images of women are a frequent icon of the human geography of the tourist destination in the media and travel literature, where they represent a superficial morphology of the land and the "motherly" attention given to family, community, and guests. Contrarily, such stereotypes are also employed to portray and typify female tourists as "wild girls gone bad," in search of romantic trysts with "exotic" male companions (figure 2). Even on the Internet, many women's websites highlight the tips they provide those female travelers who seek "love on the road." Advisors share information about cosmetics and "must have" clothing for dates, and enthusiastically encourage their readers to be "gusty" when traveling, as more women engage in casual sexual encounters in foreign destinations - as one example, $43 \%$ of the female visitors to Jamaica recently reported having sex with someone they met while on vacation, a number approaching the $69 \%$ of the male visitors who had similar interpersonal and intercultural contacts (Coleman and Crang, 2002; Lew, et al., 2004).

[Figure 13.2 about here ] 


\section{Chapter Thirteen}

The roles of many indigenous women are further conflicted by their dual service as consumer, and as cultural broker and "producer" of the tourist "product," and by political and socioeconomic policies that determine land ownership, worker mobility, and gender equality. In countries and communities around the world, disputes continue over the appropriate sexual roles and social "place" of women (and by default, men) in the cultural landscape of the tourist destination, as well as the questionable imposition of a "tourist culture" on the community, with women as the cultural attraction. These disagreements are typically manifested in the lack of control afforded women over personal and community decisions; the limited access of women to funding and jobs as tour providers and travel operators; and the variegated assessments offered by both sexes of tourism's impacts on themselves and the destination. While the intensity and outcome may differ by locality, the critical issues they share involve lifestyle choices of marriage and motherhood, one's place of residency (rural/urban), and family status (income or assets), as well as professional constraints, including sexual discrimination and violence against women and girls, and educational and occupational disparities (Ringer, 1998; Swain and Momsen, 2000; Apostolopoulos and Gayle, 2002; Gmelch, 2004; Ghodsee, 2005).

Less well-documented is the nature of our sexual expressions in travel, including ways in which gender guides our view of the destination, its accommodations and activities, and our interactions with local inhabitants. This omission is compounded by a tendency in some surveys to treat women and men, and the communities in which they reside, as homogeneous in thought and action. Yet, membership in any community shifts with individual agendas and the issue under debate, necessitating greater awareness of the multiple ways in which people conceive their surrounding environments, and the emotional and economic values and functions attached to each (Momsen and Kinnaird, 1993; Hawkins, 1994; Barry, 1995; Cohen, 1996; Howe, et al., 1997; Opperman, 1998; Hemmati, 1999). Th e r e is a crucial need, therefore, to move beyond descriptive studies of gender and travel in order to better

understand social processes and the sexually demarcated space of local places. To do so successfully will require a panoptic vision informed by direct observation and verifiable information provided by both male and female participants engaged in the leisure activity. Though highly subjective, and perhaps more 


\section{Chapter Thirteen}

emotive and qualitative than empirically quantitative, such data it is invaluable in that it is informed by personal experience. As such, even a modicum of understanding the commonalities and differences however subtle the aggregation - may help us to meaningfully bridge the current gaps that impede women and men as equal participants in the long-term success of many tourist attractions and destinations.

Tourism presents considerable potential to satisfy local desires for sustainable income generation and poverty elimination, and to provide meaningful, informed interactions for cultural sharing and networking. Achievement of these possibilities could help equalize the uneven political, economic, and social roles that now define many women and men through travel and thereby, enable more people to directly participate in, and benefit from, the informative and profitable outcomes of community-supported recreation, education, and conservation. At the same time, though recent critiques of gender in leisure studies focus on tourists and the travel industry as agents of social change, several critical themes remain underappreciated, including the commercialization of local sites, people, and cultures for visitor activities; the marginalization of "host" communities, including the commodification and subjugation of women and children as tourist attractions; and the production and privatization of tourist landscapes and services. As a result, the meaning and value of daily practices and social behavior that define a group of people and their places are casually removed from the planning matrix with a rhetorical razor that effectively disempowers community authority and disenfranchises residents (Sinclair, 1997; Ringer, 1998; Sharpley and Telfer, 2002; Swain and Momsen, 2002; Ringer, 2004).

To better understand the apparent paradox which tourism presents its destinations, this chapter presents an analysis which applies cognitive mapping techniques to graphically elucidate the structure, identity, and meaning of the destination for tourists and local people alike, as their shared "attractions" become further embedded in the global tourism economy. Using Geographic Information Systems (GIS) to adjust the resolution and scale, environmental perceptions were gathered from visitors and residents of selected rural destinations in North America and the Pacific, as the inhabitants transition from barterbased economies and natural resource extraction to sustainable tourism attraction. These composite maps were then overlaid atop physiographic and demographic data of each "host" community. This 


\section{Chapter Thirteen}

allowed community planners and leaders to visualize the patterns and consequences of recreation and tourism over time as visitation grows. Such images - through the social and recreational activities and gendered roles which they reflect - can suggest probable challenges and outcomes for socially, ecologically, and economically sustainable tourism at the local and regional level.

The mapping component also provided important details about the zones of visitor: resident interaction and associated behavior, and helped identify areas deemed to be either ecologically or aesthetically significant, or culturally "sacred." In this manner, the cognitive maps articulate tourism's function as both agent and process in the creation and cognizance of social identity, needs, and expectations for all participants, and suggest critical pathways for its implementation and success in the destination community. By further exploring how people see and act within their immediate environs, it may be possible to learn even more about the human construction and communication of tourist "attractions," including the manner by which the tourist "product" becomes feminine or masculine in its marketing and reproduction of kinship systems in society as a whole (Hall, 1969; Gould and White, 1986; Magi, 1989; Momsen and Kinnaird, 1993; Kinnaird and Hall, 1994; King, 1996; Kempadoo, 1999; Pizam and Mansfeld, 1999; Mansvelt, 2005).

\section{Experience Assessment}

Visitor choices regarding preferred activities are influenced by a number of factors. Among the most decisive are the geographic location of a destination and its relative ease of access, and the natural and social conditions of the site, including ecological and ethnic diversity, and the perceived "attractiveness" of the available options for entertainment and recreation. Equally pivotal is the presumed "authenticity" of indigenous practices and history, a perception shaped by the level and character of interaction between visitors and residents, the expectations and realizations of both in promoting tourism, and individual responses formed by gender, ethnicity, education, and other demographic factors. Our preferences for certain leisure activities, and the use of the recreational spaces which surround them, reflect a broad range of personal views, visions, and values that are both socially and sexually constructed from ritualized 


\section{Chapter Thirteen}

systems of belief and practice. Gendered through individual acts of creation, presentation, and consumption, the choices we make as tourists reflect our personal motivations for travel and reveal much about their connection to specific destinations, the experiences we seek upon arrival, and the steps we take to actively manage and minimize our impacts. Organized, summarized, and localized through patterns of communal behavior and our recollections of the spatial environment, they further reveal "a tourist landscape both physically and emotionally bounded by features that may simultaneously reassure, identify, satisfy, or disquiet the viewer" (Gould and White, 1986: 47; see also Hall, 1969; Aitchison, et al., 2000; Reynolds, 2004)

The natural and cultural environments of a destination are the means by which it will achieve international recognition and attraction tourists. However, the distinctive, socially constructed landscape of local people, and the knowledge contained therein, are too frequently obscured by the industryconstructed image of the tourist environment and, with it, the stories of the human community, nature, and the history of both. These metaphors of situation and function are crucial, though, in articulating the relationships that people establish with one another and the local environment, and in highlighting distinctive social values that form the basis of community narratives and institutional practices, and have historically served to moderate social and political change and tension (Redclift and Sinclair, 1991; Hall, 1993; Harvey et al., 1995; Pizam and Mansfeld, 1999; Enloe, 2000).

By establishing the sentiment evoked by specific recreational activities, mental maps thus provide a palimpsest of the recreational landscape and its social history, reflecting a topology of experience that is both defined and distorted by our encounters with tourism at the local level, and by our own sexual identity. They also distinguish the space of the visitor from the inhabited place of local people and thus, draw further attention to the challenges faced by women and minorities in society overall, the influence of traditional power structures (including patriarchy) and sexually prescribed tasks and behavior, the availability of capable facilitators both inside and outside the community, and the degree of local support for long-term goals (Richter, 1998). As such, they enable us to better assess the experiential meanings of varied tourist activities for various users over time, including age- and gender-related interests and 


\section{Chapter Thirteen}

impacts specific to the destination and its recreational attractions and facilities. Understanding these cognitive perceptions may allow us to proactively anticipate and manage the transitory and often spontaneous nature of the tourist visit itself by correlating expected and observed visitor behavior with the images presented in travel brochures, on the Internet, and in the media. Such a holistic assessment will hopefully broaden our understanding of the extent to which tourism shapes the experience of travel, as defined by the gender, language, perceptions, motivations, expectations, and identities of both visitors and their "hosts."

\section{Wrangell-St. Elias National Park \& Preserve, Alaska, USA}

Research undertaken between 1989-2004 in the twin Alaska "ghost" towns of Kennicott and McCarthy proposed a new direction in tourism studies, one that recognizes a socially-defined landscape often overlooked in the traditional literature of tourism, leisure, and hospitality. Through the values and meanings ascribed by visitors, residents, and the tourism industry - including those socially constructed and those taken for granted - communities become tourist destinations, interpreted and defined within a larger cultural and physiographic network. Abandoned in 1938, Kennicott and McCarthy were "rediscovered" in 1989 by outdoor recreationists, and the mountains and national park that once shielded them now beckon to ever-increasing numbers of tourists. Since 1989, the number of short-term visitors alone has increased by nearly $1,000 \%$, augmented by a swelling number of seasonal residents and small service providers, and the situation shows no signs of abating in the near future. Instead, by the year 2020, the U.S. National Park Service Regional Office in Alaska estimates recreational visits to the park and preserve will exceed 152,200 persons a year (or more than triple the total recorded in 2005). Because of the tourism growth, and the disproportionate number who now opt to stay in the two towns, rather than camp in designated wilderness areas as was the norm through the early 1990 s, friction is growing among residents who struggle to cope with the demand. Though the intensity of the conflict is relatively new to these communities, whose members have long prided themselves on their ability to govern by consensus, it is certainly not rare in other Alaskan towns and villages, where tourism and outdoor recreation-oriented 


\section{Chapter Thirteen}

retail trades and services now constitute the dominant element of the regional economy.

Anxious to ascertain the extent to which changing expectations were affecting individual perceptions and behavior, the research project was initiated to 1) collect demographic and cognitive data as a baseline for documenting future change, and 2) encourage a proactive, community tourism plan by giving form to the experiential landscapes of those who come to Kennicott-McCarthy. More specifically, the study sought, first, to use cognitive mapping techniques to determine how people perceived the two towns and the multiple landscapes that envelope them: physical, social, and historic? Second, what place experiences were reflected in the mapped images of the different groups who used the area, including the functional or emotional quality served by different landscape features, and what do they suggest for natural and recreational resource managers who seek to control the visitor experience and conserve the environments upon which it depended? The desire was to ascertain whether environmental perception might assist park planners to cope with the increased tourism, while simultaneously preserving opportunities for community development and the rural lifestyle and identity that characterizes the Alaskan "Bush." Although the qualitative nature of cognitive mapping presents some difficulty for those who prefer the statistical "accuracy" of quantitative measurements, such maps excel in making obvious the emotional significance that residents and visitors attach to communities like Kennicott-McCarthy.

For the exercise, participants in the assessment were asked to draw maps of the immediate area, pinpointing sites where they recreated or socialized, without reference to base maps and or geographic references. This step minimized subjective biases and predetermined responses that might result from symbolic suggestions of omission or inclusion. The use of freehand maps also encouraged participants to depict a wider range of activities over a broader area, rather than the constricted responses so often produced when topographic positions and elevations are specified (Gould and White, 1986; Magi, 1989; Momsen and Kinnaird, 1993; King, 1996; Ringer, 1996, 1997; Coleman and Crang, 2002). Selected groups of residents and nonresidents were evenly divided in gender and closely matched in age, though residents tend to be younger on average. Both groups were also predominantly well-educated, though residents possessed a disproportionately greater number of graduate degrees. This unexpected finding 


\section{Chapter Thirteen}

astonished those tourists who presume local people to be illiterate because of their rural, subsistence lifestyles.

Nearly half of the visitors $(40.7 \%)$ obtained their information and motivation for the trip from the personal recommendations of friends and family, and only secondarily from travel sources (35.2\%) or the U.S. National Park Service (6.5\%). This contradicts the assertions of some local people who hold the Park Service most responsible for the tourism growth though, certainly, the park itself serves as an attraction. Both residents and tourists recognize similar landscape features, though visitors were less knowledgeable beyond the immediate environs of the towns or their accommodations. As a result, they most frequently described the park in terms of the scenery surrounding the old mining buildings, and the recreational opportunities afforded by the glacier and mountains nearby (figure 13.3a). Residents, in contrast, rely on the physiographic landscape to establish both implicit and explicit territorial boundaries. For them, the allure of the park lies as much in the social relationships that govern their viably functioning mining community, as it does in the aesthetic and historic qualities that entice visitors (figure $13.3 \mathrm{~b}$ ). Collectively, the results depict a postmodern environment delineated by the behavior of tourists and residents alike, reflecting an eclectic framework of ideas, experiences, and expectations derived both anecdotally and directly, with the evidence laid out in the historically-contingent, socially-constructed character of the emergent destination. In this manner, the collection of "place" images more fully illuminates the critical role that tourism development plays in shaping the morphology of Kennicott and McCarthy as travel destinations, through the influx of new ideas and changing patterns of social behavior.

[Figures 13.3a and 13.3b about here]

\section{Kosrae, Federated States of Micronesia}

Cognitive mapping techniques were also employed to examine the qualitative effects of tourism on the Micronesian island of Kosrae, now in transition from a patriarchal, subsistence-based society to a world 


\section{Chapter Thirteen}

destination for marine tourism. Approximately 1.5 million visitors travel to the Pacific islands each year, most journeying to Guam or the Republic of Belau, where the tourist infrastructure is highly developed and there are established airlinks with Japan and Australia. However, Kosrae has slowly gained some popularity, and now ranks third in total arrivals in the Federated States of Micronesia (FSM), with nearly 3,000 visitors a year. Though this number might appear insignificant compared to other destinations in the East Asia-Pacific region, the impact is disproportionately higher because of the island's topography and the relative isolation and traditional nature of Kosraean culture (PATA, 1992; Hall, 1993; Lockhart, et al., 1993; Apostolopoulos and Gayle, 2002; Ringer, 2004). The abundance of visitor-subsidized attractions in the Pacific is clear evidence of tourism's significant financial contribution to the regional economy. Yet, its role in diminishing the meaning of local practices and places as tourist venues also demands attention. In fact, the continued emphasis on tourism's economic benefits diverts attention from "possibly the biggest issue tourism [faces] ... and its most serious restraint ... its potentially-damaging impact on the people and places visited" (PATA, 1992: 3). However profitable the monetary gain for Kosraean government and businessowners, it is the support and hospitality of the island residents who will ultimately determine tourism's survival and success (Ringer, 1992).

Research and anecdotal evidence provided by Kosraean residents stress tourism's influence in everyday life, mediating the formation of local identities and cultural patterns of behavior and communication through the parameters of its development. At the same time, these socially constructed geographies and expectations are frequently marginalized in the plans and aspirations of visitors and developers. Many Kosraeans believe the growing popularity of tourism, regionally and worldwide, is solid proof of its potential to spur local development. However, less than 10 percent of the population had ever ventured off the island until the late 1990s, and the international media remains the primary source for many islanders to assess tourism's probable impacts. As a result, there is no apparent community consensus over tourism, and some village leaders are opposed to the undesirable social effects they associate with the tourism industry in other Pacific island destinations. Nevertheless, tourism has tremendous potential to become a viable industry on Kosrae as the state seeks economic independence 


\section{Chapter Thirteen}

from the U.S.A. The challenge, therefore, for residents and industry leaders alike, is to identify activities that attract tourists interested in the natural and human environments of Kosrae, minimize their social impacts, and ensure tourism direct benefits community residents.

Community roles on Kosrae have traditionally been defined by family affiliation, villages of residency, and gender. Men work primarily in woodworking and subsistence agriculture, while women engage in weaving, fishing, or catch mangrove crabs for local use or purchase by visitors. Like many Pacific islanders, older Kosraeans have also retained the aptitude to traverse long distances on land and water with only cognitive imagery, rather than formal maps. This knowledge of spatial perception is also evident in their stories and architecture, and the way in which information of distance and location is woven into their daily lives. Determined to preserve this cultural framework while promoting expanded tourism, the Kosrae State Division of Tourism initiated a comprehensive, community-based assessment. One component of the project entailed a limited study in 1998 involving cognitive perception of residents and visitors regarding their activities and attitudes about ecotourism on Kosrae. Respondents to the cognitive mapping exercise were asked to depict and label the physical landscape according to its perceived function (path, landmark, activity center, neighborhood or community, and boundary or edge, whether physical or perceptual).

Upon completion, a composite map of the multiple images was used to designate selected community sites for special management and protection. The synthesized maps were also employed to distinguish the behavior of residents, who exhibited greater appreciation of the natural history and environments of Kosrae, from those of visitors, whose maps reflected a narrower range of place experiences, and an emphasis on tourism facilities and physical landmarks. Notable demographic differences of age, gender, and village of residency further distinguished the representations of Kosraeans. While the total number of participants was statistically insignificant (less than $1 \%$ of the island's population and visitor population was surveyed), it was deemed sufficient to establish a baseline to monitor future change as tourism evolves on the island.

Perhaps unsurprising, the dominant images of tourists are the natural features depicted in travel 


\section{Chapter Thirteen}

publications, indicating that most come to see Kosrae's scenic marine environment and mountainous interior. Rare are indicators of the island beyond the hotels, restaurants, or dive shops, and absent from most of the visitors' maps are the five villages in which Kosraeans dwell. On the maps of residents, however, is more detailed information regarding the human landscape. Populated by individual homesteads and family names, the fields and groves of the men and the canals and fishing sites of women, every village is identified through symbols of human history and gendered practice. Extending beyond the visitor periphery, the diversity of cultural landscapes included evidence of social organization by gender in the depictions of older Kosraean adults, whose images reflected their separate work spheres and knowledge (figure 13.4a). This gender difference is, however, missing from the maps of younger Kosraeans, whether male or female. Instead, Kosraeans under age 40 of both sexes share a greater awareness of the island as a whole than do their elders, due in part to jobs in the tourism industry, which enable them to traverse the island and become better acquainted with its ecology (figure 13.4b).

[Figures 13.4a. and 13.4b about here]

Such data, however subjective, should therefore prove useful to tourism planners and developers, who may consider communities and tourists to be homogeneous, when in reality both categories are widely heterogeneous and frequently hold dissimilar notions of tourism as an appropriate tool of economic development. The variety in perceptions and experiences of place further underscore the critical role that tourism plays in shaping the human mosaic of travel destinations. The cultural construction of the tourist destination, which is as much a process of "place creation" as it is one of community revival, represents a direct link between expectation and realization filtered through local beliefs and behaviors that produce widely varied outcomes. A failure to consider these variations fully from the perspective of different users (visitor/resident, male/female, adult/youth) may thus seriously hinder efforts to understand tourism's longterm impacts on the broader community. 


\section{Chapter Thirteen}

\section{Conclusion}

Part of tourism's appeal is the opportunity it provides both visitors and residents to immerse themselves in another place and persona, and to engage other people and cultures directly. In search of cultural immersion and environmental education, tourism may however lead to the marketing of culture and the pursuit of the exotic, rather than an affirmation of local culture. The situation is further aggravated by the lack of experience and expertise in many communities in reconciling the sometimes opposing goals of economic growth with cultural and ecological preservation. As a result, a central issue for many tourism

proponents and opponents is the long-term consequences of gradually replacing a social landscape that has evolved through time, in-situ, with one that caters primarily to visitors' stereotypes while at the same time, trying to conserve finite resources and increase awareness among young residents of their own cultural history and gender identity?

While destinations worldwide welcome the ever increasing numbers of domestic and international tourists, there is corresponding awareness of tourism's paradox: in fostering economic growth, tourism may also threaten - directly and indirectly - the cultural environment that sustains local people and constitutes their identity. Many of the social and behavioral transformations associated with tourism development and other modernization processes are readily apparent to the casual visitor, including the preference for imported food, clothing, music, and movies. Yet, only a position of social intimacy reveals the inhabited, socially constructed form beneath the distractions of the tourists, a seemingly intangible structure around which women and men learn to communicate, play, motivate and navigate. Though admittedly highly personalized and localized, the contours of this behavioral landscape may be as influential in determining the effectiveness of sustainable tourism and community planning processes as the presence of more scientifically established "facts."

If tourism is to prove successful then, careful thought must therefore be given to the ability and willingness of local community leaders to evaluate and absorb the potential communal and social costs that tourism development will entail. A successful resolution requires the implementation and acceptance of appropriate management policies that provide clear, long-term benefits to both tourist and resident, and 


\section{Chapter Thirteen}

create positive links between recreational interests, nature and cultural conservation, and visitor education and destination choice. These, in turn, require a development model carefully attuned and responsive to the perceptions and expectations of the people of the destination. The expansion of tourism around the globe affords women and men both opportunities and challenges, as they negotiate new gender roles and identities in a social landscape still defined in many countries by patriarchal rule and sexually restrictive practices. Whether defined as sex, companionship, romance, or an interactive cultural experience with someone outside the community, the nature and context of social interaction and empowerment through travel are rapidly evolving. The consequences of such change may include more economic power for women, as well as greater expectations for future profitability and employability through education and a greater diversity of occupational choices. At the same time, the "unbalancing" of traditional marital roles may lead women to devote less time to child-rearing and housework and other social changes.

Tourism may also further perpetuate the "male" practices of prostitution by capitalizing on the limited opportunities afforded local men for economic prestige and power. As tourists, women possess greater power in defining and controlling their own relationships with indigenous men, with an increase in emotional conflicts for men as they experience a loss of economic control, and a sense of manipulation of both local women and men for personal gain. The end result is a reproduction and reinforcement of racial and cultural superiority and domination over the "hosts" of the destination. Consequently, there is a need to explore alternative ways in which tourism, as an industry and a recreational activity, can strengthen the potential for change in current conditions, particularly in terms of facilitating proactive collaboration between community residents and tourists, and in the selection of marketing images and media venues. In addition, there is a need to defend women from complaints that the creation of tourism jobs further reinforces inauthentic practices and beliefs, and the loss of traditional family lifestyles through social and political change.

The key, perhaps, is to take specific steps to maintain or revive authentic cultural practices and art, to educate visitors about prostitution and other inappropriate social impacts, and to minimize sexual misunderstandings between tourists and residents. It is here that cognitive maps may prove useful, for 


\section{Chapter Thirteen}

they make visible "our place in the world [and the manners by which we define and] orient ourselves" (King, 1996: 40). Any map is, admittedly, an imperfect portrayal of a world both chaotic and complex. Consequently, there are undeniable weaknesses with this methodology, including a reliance on data that is distorted by personal experience, miscommunication, and generalized observations, and limited by time and ethnocentrism. However, such images do provide a tangible evidence of the multiple "places" experienced by tourists and inhabited by residents as they negotiate the destination. This functional overview of the tourist landscape graphically reflects the activities and contact zones in which residents and nonresidents directly engage, providing meaningful indicators of change in the past and of possible trends in visitor interests and resident (dis)satisfaction in the future. Also apparent are more abstract networks delineated by kinship and gendered roles in society. Through such visual and emotive insights, perceptual maps provide much-needed access to local processes and relationships organized by function

and form. They also help dispel the persistent notion that indigenous communities are always relatively homogeneous. Instead, the highly personalized and fragmented nature of the mental maps submitted by local residents and visitors to the destinations described in this text demonstrate the variability and subjectivity of place attachment and gender identity. While the images are certainly generalized and superficial in their presentation of what is real, they are critically influential in creating a common sense of community and identity.

Continued analysis of such maps would therefore enable community planners and managers to visualize and interpret variations in the meaning and structure of social symbols and territory, and thereby, better understand, and sensitively anticipate, problems of development before they arise or take hold. Through the insertion of individual perceptions of visitors and residents in the process, graphic evidence of existing social behavior, community identities, and associated landscape values is displayed for consideration by decision-makers, and provides a baseline against which future cognitive and tangible modifications can be documented. By enabling community leaders and planners to see the destination as its users currently do, such insights would substantially improve our understanding of the gender segregation and impacts reflected in the discourse, function, and communication of local identity. Greater 


\section{Chapter Thirteen}

appreciation of the qualitative and emotional effects of tourism may also facilitate the development of facilities and activities that support local efforts to improve health care and access to technology and financial credit for women, and enhance the dignity of women by equalizing work disparities and dispelling the common view of women as "cheap" labor. Only in such a manner will we succeed in fostering travel that is ecologically sustainable and socially empowering in recreation settings worldwide.

\section{Acknowledgments}

The author wishes to express appreciation for the financial support provided by the Center for the Study of Women in Society at the University of Oregon in undertaking some of the research presented in this paper. I also wish to thank the women and men of Micronesia and Alaska for their willingness to participate in my studies of the experiential landscapes of tourism in their communities, and most especially to Teresa Weaver for her continued support and understanding. 


\section{Chapter Thirteen}

\section{References}

Apostolopoulos, Y., and D. Gayle (eds)(2002) Island tourism and sustainable development: Caribbean, Pacific, and Mediterranean experiences. Praeger Publishers, Westport, CT.

Apostolopoulos, Y.; S. Sonmez; and D. Timothy (eds)(2001) Women as producers and consumers of tourism in developing regions. Praeger Publications, Westport, CT.

Aitchison, C.; N. MacLeod; and S. Shaw (2000) Leisure and tourism landscapes: social and cultural geographies. Routledge, London.

Barry, K. (1995) The prostitution of sexuality. New York University Press, New York.

Cohen, E. (1996) Thai tourism: hill tribes, islands, and open-ended prostitution. Studies in Contemporary Thailand \#4, White Lotus, Bangkok.

Coleman, S., and M. Crang (eds)(2002) Tourism: between place and performance. Berghahn Books, London.

Enloe, C. (2000) Bananas, beaches and bases: making feminist sense of international politics. University of California Press, Berkeley.

Ghodsee, K. (2005) The red Riviera: gender, tourism, and postsocialism on the Black Sea. Duke University Press, Durham, NC.

Gmelch, S. (2004) Tourists and tourism: a reader. Waveland Press, Long Grove, IL.

Gould, P., and R. White (1986) Mental maps, $2^{\text {nd }}$ ed. Allen \& Unwin, Boston, MA.

Hall, C.M. (1993) Tourism in the Pacific: development, impacts and markets. Longman Cheshire, Melbourne.

Hall, E.T. (1969) The hidden dimension. Doubleday, Garden City, NJ.

Harvey, M.; J. Hunt; and J.R. Harris (1995) Gender and community tourism dependence level. Annals of Tourism Research 22: 349-68.

Hawkins, D.E. (1994) Ecotourism: opportunities for developing countries. In Global tourism: the next decade, (ed.) W. Theobald. Butterworth-Heinemann Ltd., London, pp. 261-73.

Hemmati, M. (ed.)(1999) Gender and tourism: women's employment and participation in tourism. UN 


\section{Chapter Thirteen}

Environment and Development Forum, UK Committee, London.

Howe, J.; E. McMahon; and L. Propst (1997) Balancing nature and commerce in gateway communities.

Island Press, Washington, D.C. and Covelo, CA.

Kempadoo, K. (ed.)(1999) Sun, sex, and gold: tourism and sex in the Caribbean. Rowman \& Littlefield

Publishers, Lanham, MD.

King, G. (1996) Mapping reality: an exploration of cultural cartographies. Macmillan Press, London.

Kinnaird, V., and D. Hall (eds)(1994) Tourism: a gender analysis. Wiley, Chichester, NY.

Lew, A.; C.M. Hall; and A. Williams (eds)(2004) A companion to tourism. Blackwell Publishing Ltd., Oxford, UK.

Lockhart, D.G.; D. Drakakis-Smith; and J. Schembri (eds)(1993) The development process in small island states. Routledge, London and New York.

Magi, L.M. (1989) Cognition of recreation resources through photographic images. South African Geographical Journal 71: 67-73.

Mansvelt, J. (2005) Geographies of consumption. Sage Publications, Inc., London.

Momsen, J.H., and V. Kinnaird (eds)(1993) Different places, different voices: gender and development in Africa, Asia, and Latin America. Routledge, London and New York.

Opperman, M. (ed.)(1998) Sex tourism and prostitution: aspects of leisure, recreation and work. Cognizant Communication, Elmsford, NY.

Pacific Asia Travel Organization (1992) PATA conference daily. PATA, Hong Kong.

Pizam, A., and Y. Mansfeld (eds)(1999) Consumer behavior in travel and tourism. The Haworth Hospitality Press, New York.

Redclift, N., and M. Sinclair (eds)(1991) Working women: international perspectives on labour and gender ideology. Routledge, London and New York.

Reynolds, N. (2004) Geographies of writing: inhabiting places and encountering difference. Southern Illinois University Press, Carbondale.

Richter, L. (1998) Exploring the political role of gender in tourism research. In Global tourism: the next 


\section{Chapter Thirteen}

decade, $2^{\text {nd }}$ ed., (ed.) W. Theobald. Butterworth-Heinemann, Oxford, pp. 391-404.

Ringer, G. (1992) Nature-based attractions development project: assessment and management plan. Kosrae State Divison of Tourism, Tofol, Federated States of Micronesia.

Ringer, G. (1996) Wilderness images of tourism and community. Annals of Tourism Research 23 (4): $950-$ 53.

Ringer, G. (1997) Beyond the boundaries: social place in a protected space. GeoJournal 41(3): 223-32.

Ringer, G. (2004) Geographies of tourism \& place in Micronesia: the 'sleeping lady' awakes. The Journal of Pacific Studies 26 (1-2): 131-50.

Ringer, G. (ed.)(1998) Destinations: cultural landscapes of tourism. Routledge, London and New York.

Ryan, C., \& C.M. Hall (2001) Sex tourism: marginal people and liminalities. Routledge, London and New York.

Sharpley, R., and D. Telfer (eds)(2002) Tourism and development: concepts and issues. Channel View Publications, Clevedon, UK.

Sinclair, M.T. (ed.)(1997) Gender, work and tourism. Routledge, London.

Swain, M., and J. Momsen (eds)(2002) Gender/tourism/fun(?). Cognizant Communication, Elmsford, N 


\section{Language}

\section{Attraction}

\section{Commodity}

\section{Image}

Social space

\section{Employment}

Motivation

\section{Icon}

Constructed place

Ownership

Access

\section{Impact}


1. Vlrarade

2 Nbtechsills

3 Odenventenuriterededintrad

4 Scia" "scape"pinatyndive

5 Detaloieted

6 Caregier

7. Soxandsfefysyntuds

8 Alvermareh roserd

Surce Sudbtsney(n=24), Utivesityd Cogn LSA Neyzor 


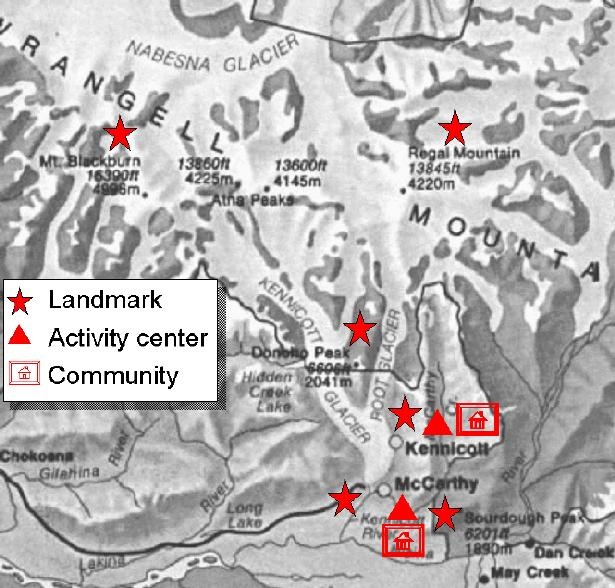




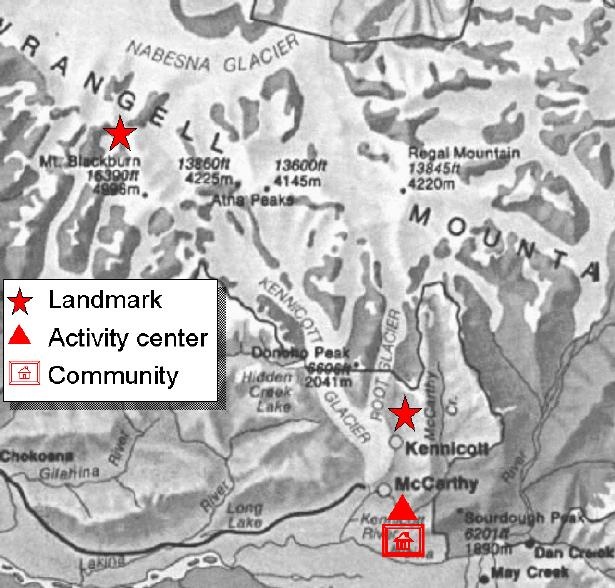




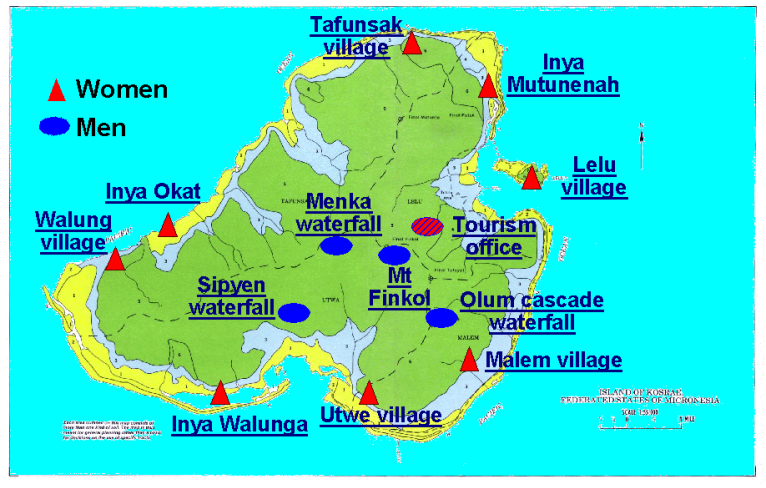




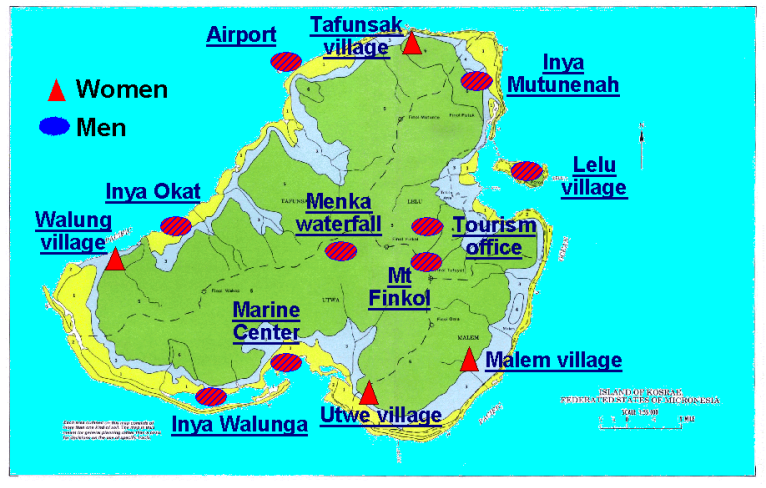

